\title{
Familial-Related Risks for Congenital Hypothyroidism in Iranian Newborns: A Population-Based Case-Control Study
}

\author{
Shahin Yarahmadi (iD) ${ }^{1}$, Nasrin Azhang (iD) ${ }^{1}$, Mahmood Salesi (iD) ${ }^{2,3}$ and Khaled Rahmani (iD) ${ }^{4, *}$ \\ ${ }^{1}$ Department of Endocrinology and Metabolism, Ministry of Health, Tehran, Iran \\ ${ }^{2}$ Chemical Injuries Research Center, Systems Biology and Poisoning Institute, Baqiyatallah University of Medical Sciences, Tehran, Iran \\ ${ }^{3}$ Research Center for Prevention of Oral and Dental Disease, Lifestyle Institute, Baqiyatallah University of Medical Sciences, Tehran, Iran \\ ${ }^{4}$ Liver and Digestive Research Center, Research Institute for Health Development, Kurdistan University of Medical Sciences, Sanandaj, Iran \\ "Corresponding author: Liver and Digestive Research Center, Research Institute for Health Development, Kurdistan University of Medical Sciences, Sanandaj, Iran. Email: \\ khaledrahmani111@yahoo.com
}

Received 2020 May 12; Revised 2020 November 19; Accepted 2020 December 23.

\begin{abstract}
Background: Congenital hypothyroidism $(\mathrm{CH})$, as one of the most common endocrine disorders, is a preventable cause of mental retardation.

Objective: This study aimed to identify familial-related risk factors for $\mathrm{CH}$ in Iranian newborns.

Methods: A population-based case-control study was performed on the National Registry System of patients with $\mathrm{CH}$ in Iran. In this study, 906 controls and 454 cases were studied for one year. Familial related factors were investigated using logistic regression models. Population attributable fraction (PAF) was also calculated for each significant risk factor.

Results: Using multivariate analysis, an increased risk for $\mathrm{CH}$ was observed in patients with congenital anomalies (odds ratio (OR): 5.77, 95\% confidence interval (CI): 2.37 - 14.01), history of mental retardation in family (OR:2.10, 95\% CI: 1.15-3.83), mother's hypothyroidism during pregnancy (OR: 2.01, 95\% CI: 1.33 - 3.03), intra-family marriage (OR:1.49, 95\% CI: 1.18 - 1.89), gestational diabetes (OR: 1.69, 95\% CI:1.09 - 2.63), having a hypothyroid child in the family (OR:2.48, 95\% CI:1.39 - 4.42), and twins or more (OR: 2.61, 95\% CI:1.31 - 5.21). The highest PAF among familial-related risk factors for $\mathrm{CH}$ is related to the intra-family marriage (14.9\%).

Conclusions: This study revealed that familial-related risk factors and consanguine marriages play an essential role in the high incidence of $\mathrm{CH}$ in Iran. About $15 \%$ of $\mathrm{CH}$ in Iran could be attributed to intra-family marriage alone.
\end{abstract}

Keywords: Congenital Hypothyroidism, Newborn Screening Program, Familial Risk Factor, Intra-family Marriage, Population Attributable Fraction

\section{Background}

Congenital hypothyroidism $(\mathrm{CH})$ as a partial or complete loss of function of the thyroid gland affects neonates from birth (1). In this disease, the function of iodinecontaining hormones that have an important role in metabolism, regulating growth, and brain development is disrupted due to inadequate thyroid hormone production that can be resulted from an inborn error of thyroid metabolism, defect in the gland, and iodine deficiency (2, 3). The clinical manifestations of $\mathrm{CH}$ are often subtle and, in more cases, not present at birth, likely because of the transplacental passage of maternal thyroid hormones. Increased sleep and decreased activity, feeding difficulty, constipation, and prolonged jaundice are common symptoms of children with $\mathrm{CH}(4,5)$. According to new evidence,
$\mathrm{CH}$ can be a risk factor for central hearing process disorders (6). This endocrine disorder can be detected on newborn screening, and infants who are identified in the first month have the best prognosis for optimal mental development (7).

Newborn screening programs for $\mathrm{CH}$, which are primarily implemented in developed countries, provide the opportunity to investigate the pathogenesis and etiology of $\mathrm{CH}$ (8). Prior to the newborn screening program, the diagnosis of $\mathrm{CH}$ was based on clinical signs and symptoms, and the incidence was 1:7,000 to 1:10,000 (9). According to the current evidence, the recall rates of neonates, vary from $0.01 \%$ to $13.3 \%$ in different countries (10). Based on the reports obtained from data of national newborn screening programs in many regions, especially in the developed countries, $\mathrm{CH}$ occurs in approximately 1:2000 to 
1:4000 newborns in many areas of the world, whereas $\mathrm{CH}$ incidence in Iran is higher. In Iran, where $\mathrm{CH}$ incidence is 1:650 live births, the national neonatal screening program for $\mathrm{CH}$ was established in 2004 and progressively developed all over the country $(11,12)$. All the Iranian public health centers that participate in the national screening program are responsible for newborn screening, treatment, and follow-up of children with $\mathrm{CH}$. The success of $\mathrm{CH}$ treatment in Iran has been reported in a previous study (13).

The incidence of $\mathrm{CH}$ in Iran is much higher than in many other countries and the global average (14). Different familial and environmental factors can influence this high incidence. In fact, $\mathrm{CH}$ is a multifactorial disease, so that many environmental, familial, and autoimmune factors play a role in its pathogenesis $(15,16)$. Previous studies about the role of autoimmune factors in the Iranian population revealed no significant role in the pathogenesis of $\mathrm{CH}$ (17). Undeniably, identifying $\mathrm{CH}$ risk factors is crucial to improving the surveillance system of $\mathrm{CH}$ in the country and can help policymakers to plan and conduct pertinent intervention programs to control the high occurrence of this congenital disorder in the country. Regarding the environmental factors, the role of iodine deficiency or excess iodine intake was investigated. Iodine deficiency had no significant role in this regard (15).

\section{Objectives}

The main aim of this population-based case-control study was to clarify the role of gestational diabetes and familial-related risk factors in the occurrence of $\mathrm{CH}$ in Iran.

\section{Methods}

\subsection{Study Design and Population}

The present research was a population-based casecontrol study conducted in Iran in 2018. The population included Iranian newborns (under 28 days) that were screened by the national newborn screening program. Study participants included 454 cases and 906 age, sex, and socio-economic-matched controls who were enrolled from 18 medical universities located in 12 of the 31 provinces in Iran that observed a high incidence of $\mathrm{CH}$. Approximately two age-matched ( \pm 1 month) and socio-economic-matched (with same geographical location) controls were recruited per case based on specific criteria. The first control per case was sex-matched, and the second control per case was not sex-matched. The study enrolment started in June-2018 and was carried out for eight months. It is noteworthy that only newly diagnosed children with $\mathrm{CH}$ screened by the public health centers were included in our study. The screening test for $\mathrm{CH}$ in the Iran national newborn screening program is performed on dried blood spots on filter paper (S\&S 903), and thyroidstimulating hormone (TSH) is measured primarily as the screening test. The positive results in the first screening test were subsequently confirmed by serum TSH and T4/ Free T4. The controls were infants born in the same maternity clinic where a new $\mathrm{CH}$ case was born. They were recruited a month before or after the $\mathrm{CH}$ diagnosis was confirmed. As mentioned earlier, the socioeconomic factor is another significant factor by which we matched cases and controls so that cases and controls in this study were residents of the same region where the screening centers were located.

\subsection{Data Collection}

A structured checklist was administrated to gather the demographic and clinical data in the same way in cases and controls. All mothers of participants were tested for thyroid function through measurement of TSH and T4 hormones.

Other variables, including parents' job, smoking status, newborn sex, gestational age at birth (term/preterm), birth delivery type (vaginal/cesarean section), and familial-related factors such as congenital anomalies, history of mental retardation in the family, intra-family marriage, gestational diabetes/diabetes mellitus in mother, and having a hypothyroid child in the family, were gathered from hospital records and interviews with the children's' parents. To collect the latter data, the parents were interviewed by trained interviewers and provided their written informed consent prior to participation in the study. The design and protocol of conducting this study were evaluated and confirmed by the ethics committee of the Kurdistan University of Medical Sciences (ID: IR.MUK.REC.1396.153).

\subsection{Statistical Methods}

Data were analyzed by STATA software (version 13) using descriptive and analytical techniques. Univariate associations were explored using the Mann-Whitney U test, Pearson's Chi-square test, and frequency table. To control the potential confounders, the possible association between familial profiles and $\mathrm{CH}$ were investigated using 
multiple logistic regression. Finally, the population attributable fraction (PAF) was calculated using Miettinen's equation for each significant risk factor. All the statistical tests were two-sided, and a P-value $<0.05$ was used to determine statistical significance.

\section{Results}

Over the course of the study, a total of 1360 infants, including 454 hypothyroid (cases) and 906 healthy (control) children, were included in the research and analyses. Twohundred and forty (52.9\%) girls and 446 (49.2\%) of the studied children were boys in the case and control groups, respectively. The participants were selected from 18 medical universities in 12 provinces of Iran (Table 1 ).

The distribution of various studied factors, demographic characteristics, and familial-related factors are summarized in Table 2 . As observed in Table 2, the association between demographic variables and $\mathrm{CH}$ was not significant in the univariate analysis, while the relationship between $\mathrm{CH}$ occurrence and all the investigated familialrelated variables was statistically significant $(\mathrm{P}<0.05)$.

To further explore the potential association between familial/genetic factors and $\mathrm{CH}$, multivariate analysis was conducted using logistic regression (Table 3 ). As indicated in Table 3, multilevel logistic regression showed that congenital anomalies are the most influential risk factor for congenital hypothyroidism in Iran, so that the chance of congenital hypothyroidism event in children who have congenital anomalies is 5.77 times higher than children without anomalies. Twins or multiple pregnancies (OR = 2.61, 95\% CI: 1.31 - 5.21), having a hypothyroid child in the family ( $\mathrm{OR}=2.48,95 \% \mathrm{CI}: 1.39$ - 4.42), history of mental retardation in the family (OR $=2.10,95 \% \mathrm{CI}: 1.15-3.83)$, hypothyroidism in mothers during pregnancy $(\mathrm{OR}=2.01,95 \% \mathrm{CI}: 1.33$ - 3.03), gestational diabetes ( $\mathrm{OR}=1.69,95 \% \mathrm{CI}: 1.09$ - 2.63), and intra-family marriage $(\mathrm{OR}=1.49,95 \% \mathrm{CI}: 1.18-1.89)$, are other significant risk factors of $\mathrm{CH}$.

The model 2 is a multiple logistic regression model adjusted for some of the covariates while the model 3 is a multilevel multiple logistic regression model with similar covariates, that universities have been considered as level of sampling and run as random intercept model.

Since PAF is one of the most important parameters for assessing the effects of risk factors and evaluating the potential outcome of preventive strategies at the community level, the value of PAF was calculated for each significant variable based on the prevalence of each risk factor in the patient group. The prevalence of familial-related risk factors, according to the studied groups, is shown in Figure 1. Among all the evaluated risk factors, the prevalence of intra-family marriage is higher, $41.9 \%$, and $33.2 \%$ in the case and control groups, respectively. The intra-family marriage risk factor had the highest PAF (14.15\%) among all the seven investigated familial factors. The PAF values for other risk factors are provided in Table 4.

\section{Discussion}

The results obtained from the present study, which is the first community-based case-control approach with adequate sample size, showed that some familial-related factors such as congenital anomalies, history of mental retardation in the family, mother's hypothyroidism during pregnancy, intra-family marriage, gestational diabetes, having a hypothyroid child in the family, and twins or more, are considered significant risk factors for the high incidence of $\mathrm{CH}$ in Iran.

The results showed that congenital anomalies are one of the risk factors of $\mathrm{CH}$ (OR:5.7, 95\%CI: 2.37-14.01). The finding is consistent with the study by Emanuela Medda et al. that reported that birth defects (OR:7.5, 95\%CI:2.9-19.0) are one of the main risk factors for $\mathrm{CH}$ (18).

One of the most important results of our study was the high frequency of intra-family marriage among parents of hypothyroid children. In general, the rate of intra-family marriages, consanguineous marriages in Iranian society is high (19), so its prevalence among $\mathrm{CH}$ and healthy children in our study was $41.9 \%$ and $33.2 \%$, respectively. The risk of $\mathrm{CH}$ in children born from parents engaged in an intra-family marriage (consanguinity among parents) is significantly 1.5 times higher than others. Our results confirmed the findings of a previous study by Hashemipour et al. in the Isfahan province of Iran that showed a significant association between parental consanguinity and $\mathrm{CH}$. According to their results, $\mathrm{CH}$ was significantly higher in newborns with 1st cousin parental consanguinity than 2nd cousin parental consanguinity (20).

The other risk factor for $\mathrm{CH}$ in this study was a twin or multiple pregnancies, so that the chance of $\mathrm{CH}$ occurrence in twin or multiple pregnancies was 2.61 times higher than other infants. This finding is consistent with other studies conducted in the southwest Khuzestan province of Iran (21) and is supported by several studies in other countries (22-24). The results also indicated that gestational diabetes 


\begin{tabular}{|c|c|c|c|c|}
\hline \multirow{2}{*}{ Province } & \multirow{2}{*}{ University Name } & \multicolumn{2}{|c|}{ Groups, No. (\%) } & \multirow{2}{*}{ Total, No. (\%) } \\
\hline & & Case & Control & \\
\hline Kurdistan & Kurdistan & $95(20.9)$ & $190(21.0)$ & $285(21.0)$ \\
\hline Chaharmahal and Bakhtiari & Shahr-e Kord & $32(7.0)$ & $64(7.1)$ & $96(7.1)$ \\
\hline Markazi & Arak & $24(5.3)$ & $48(5.3)$ & $72(5.3)$ \\
\hline Bushehr & Bushehr & $32(7.0)$ & $64(7.1)$ & $96(7.1)$ \\
\hline Zanjan & Zanjan & $32(7.0)$ & $64(7.1)$ & $96(7.1)$ \\
\hline Kohgiluyeh and Boyer-Ahmad & Yasuj & $28(6.2)$ & $56(6.2)$ & $84(6.2)$ \\
\hline Lorestan & Lorestan & $23(5.1)$ & $46(5.1)$ & $69(5.1)$ \\
\hline North Khorasan & Esfarayen & $6(1.3)$ & $12(1.3)$ & $18(1.3)$ \\
\hline Kerman & Kerman & $21(4.6)$ & $42(4.6)$ & $63(4.6)$ \\
\hline Kerman & Jiroft & $15(3.3)$ & $30(3.3)$ & $45(3.3)$ \\
\hline Kerman & Rafsanjan & $19(4.2)$ & $38(4.2)$ & $57(4.2)$ \\
\hline Kerman & Bam & $11(2.4)$ & $22(2.4)$ & $33(2.4)$ \\
\hline Khuzestan & Dezful & $23(5.1)$ & $45(5.0)$ & $68(5.0)$ \\
\hline Khuzestan & Abadan & $14(3.1)$ & $28(3.1)$ & $42(3.1)$ \\
\hline Razavi Khorasan & Gonabad & $2(0.4)$ & $4(0.4)$ & $6(0.4)$ \\
\hline Razavi Khorasan & Sabzevar & $29(6.4)$ & $58(6.4)$ & $87(6.4)$ \\
\hline Fars & Shiraz & $41(9.0)$ & $81(8.9)$ & $122(9.0)$ \\
\hline Fars & Larestan & $7(1.5)$ & $14(1.5)$ & $21(1.5)$ \\
\hline Total & & $454(100)$ & $906(100)$ & $1360(100)$ \\
\hline
\end{tabular}

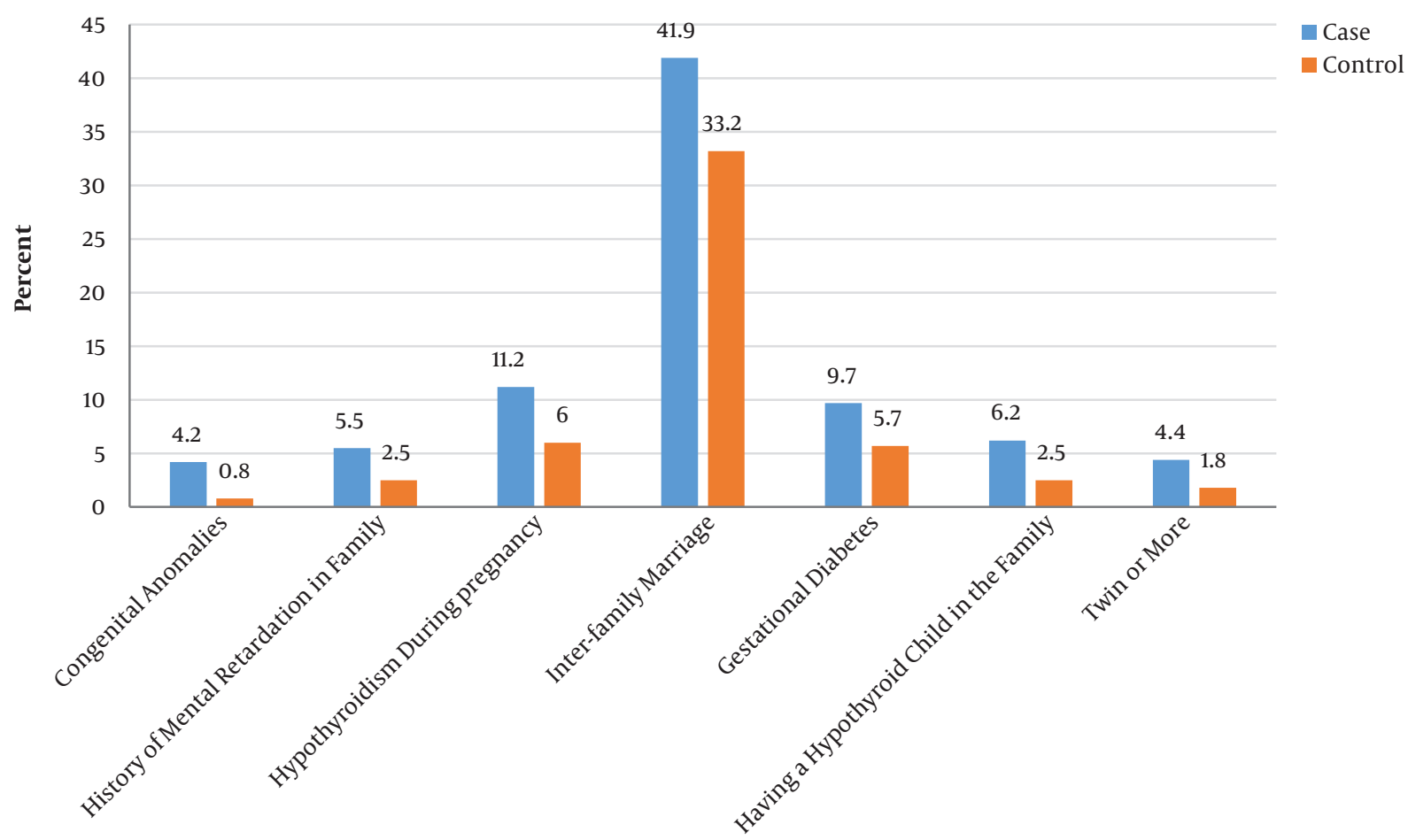

Figure 1. Prevalence of gestational diabetes and familial-related risk factors according to the studied groups. 


\begin{tabular}{|c|c|c|c|}
\hline Demographic Characteristics Category & Control $(\mathrm{N}=906)$ & Case $(N=454)$ & P-Value \\
\hline Mother's age (year), mean \pm SD (range) & $28.8 \pm 5.8(15-48)$ & $29.4 \pm 6.2(14-44)$ & $0.1^{\mathrm{b}}$ \\
\hline \multicolumn{4}{|l|}{ Mother smoking } \\
\hline No & $893(98.6)$ & $449(98.9)$ & $0.6^{\mathrm{c}}$ \\
\hline Yes & $13(1.4)$ & $5(1.1)$ & \\
\hline \multicolumn{4}{|l|}{ Mother's job } \\
\hline Unoccupied (housewife) & $839(92.6)$ & $421(92.7)$ & $0.9^{c}$ \\
\hline Occupied & $67(7.4)$ & $33(7.3)$ & \\
\hline \multicolumn{4}{|l|}{ Father smoking } \\
\hline No & $704(77.7)$ & $331(72.9)$ & $0.05^{\mathrm{c}}$ \\
\hline Yes & $202(22.3)$ & $123(27.1)$ & \\
\hline \multicolumn{4}{|l|}{ Sex } \\
\hline Boy & $446(49.2)$ & $240(52.9)$ & $0.2^{\mathrm{c}}$ \\
\hline Girl & $460(50.8)$ & $214(47.1)$ & \\
\hline \multicolumn{4}{|l|}{ Birth/delivery type } \\
\hline Natural & $531(58.6)$ & $264(58.1)$ & $0.2^{\mathrm{c}}$ \\
\hline Unplanned cesarean & $297(32.8)$ & $163(35.9)$ & \\
\hline Scheduled cesarean & $78(8.6)$ & $27(5.9)$ & \\
\hline \multicolumn{4}{|c|}{ Familial-Related Factors and Gestational Diabetes } \\
\hline \multicolumn{4}{|l|}{ Congenital anomalies } \\
\hline No & $899(99.2)$ & $435(95.8)$ & $<0.001^{\mathrm{c}}$ \\
\hline Yes & $7(0.8)$ & $19(4.2)$ & \\
\hline \multicolumn{4}{|l|}{ History of mental retardation in the family } \\
\hline No & $883(97.5)$ & $429(94.5)$ & $0.005^{\mathrm{c}}$ \\
\hline Yes & $23(2.5)$ & $25(5.5)$ & \\
\hline \multicolumn{4}{|l|}{ Hypothyroidism during pregnancy } \\
\hline No & $852(94.0)$ & $403(88.8)$ & $0.001^{\mathrm{c}}$ \\
\hline Yes & $54(6.0)$ & $51(11.2)$ & \\
\hline \multicolumn{4}{|l|}{ Intra-family marriage } \\
\hline No & $605(66.8)$ & $264(58.1)$ & $0.002^{c}$ \\
\hline Yes & $301(33.2)$ & $190(41.9)$ & \\
\hline \multicolumn{4}{|l|}{ Gestational Diabetes } \\
\hline No & $854(94.3)$ & $410(90.3)$ & $0.007^{\mathrm{c}}$ \\
\hline Yes & $52(5.7)$ & $44(9.7)$ & \\
\hline \multicolumn{4}{|l|}{ Having a hypothyroid child in the family } \\
\hline No & $883(97.5)$ & $426(93.8)$ & $0.001^{\mathrm{c}}$ \\
\hline Yes & $23(2.5)$ & $28(6.2)$ & \\
\hline \multicolumn{4}{|l|}{ Twins or multiple pregnancy } \\
\hline No & $890(98.2)$ & $434(95.6)$ & $0.004^{\mathrm{c}}$ \\
\hline $\operatorname{Yes}(\geq 2)$ & $16(1.8)$ & $20(4.4)$ & \\
\hline
\end{tabular}

${ }^{\mathrm{a}}$ Values are expressed as No. (\%) unless otherwise indicated.

${ }^{\mathrm{b}}$ Mann-Whitney U test.

${ }^{\mathrm{c}}$ Chi-square Test.

is considered a risk factor for $\mathrm{CH}$. Although in a study conducted by Medda in the Italian population, diabetes was introduced as a risk factor for $\mathrm{CH}$ (18), we did not find further studies to support this finding in the literature. Hence, we suggest conducting further studies regarding possible relationships between gestational diabetes and $\mathrm{CH}$.
We found that $36.19 \%$ of $\mathrm{CH}$ in Iran could be attributed to familial factors such as congenital anomalies, history of mental retardation in the family, the mother's hypothyroidism during pregnancy, intra-family marriage, gestational diabetes, and having a $\mathrm{CH}$ child in the family. Among these risk factors, the role of intra-family marriage with 


\begin{tabular}{|c|c|c|c|c|c|c|}
\hline \multirow{2}{*}{ Category } & \multicolumn{2}{|c|}{ Logistic Regression (Model 1) } & \multicolumn{2}{|c|}{ Logistic Regression (Model 2) } & \multicolumn{2}{|c|}{ Logistic Regression (Model 3) } \\
\hline & OR $(95 \% \mathrm{CI})$ & P-Value & OR $(95 \% C I)$ & P-Value & OR $(95 \% C I)$ & P-Value \\
\hline Congenital anomalies & & $<0.001$ & & $<0.001$ & & $<0.001$ \\
\hline No & Base category & & Base category & & Base category & \\
\hline Yes & $5.61(2.31-13.63)$ & & $5.74(2.36-13.97)$ & & $5.77(2.37-14.01)$ & \\
\hline $\begin{array}{l}\text { History of mental retardation in } \\
\text { the family }\end{array}$ & & 0.02 & & 0.02 & & 0.01 \\
\hline No & Base category & & Base category & & Base category & \\
\hline Yes & $2.04(1.12-3.69)$ & & $2.04(1.12-3.72)$ & & $2.10(1.15-3.83)$ & \\
\hline $\begin{array}{l}\text { Hypothyroidism during } \\
\text { pregnancy }\end{array}$ & & 0.001 & & 0.001 & & 0.001 \\
\hline No & Base category & & Base category & & Base category & \\
\hline Yes & $2.01(1.33-3.03)$ & & $2.02(1.34-3.05)$ & & $2.01(1.33-3.03)$ & \\
\hline Intra-family marriage & & 0.001 & & 0.001 & & 0.001 \\
\hline No & Base category & & Base category & & Base category & \\
\hline Yes & $1.48(1.17-1.88)$ & & $1.51(1.19-1.92)$ & & $1.49(1.18-1.89)$ & \\
\hline Gestational diabetes & & 0.01 & & 0.03 & & 0.02 \\
\hline No & Base category & & Base category & & Base category & \\
\hline Yes & $1.75(1.14-2.69)$ & & $1.62(1.05-2.52)$ & & $1.69(1.09-2.63)$ & \\
\hline $\begin{array}{l}\text { Having a hypothyroid child in } \\
\text { the family }\end{array}$ & & 0.003 & & 0.002 & & 0.002 \\
\hline No & Base category & & Base category & & Base category & \\
\hline Yes & $2.43(1.37-4.32)$ & & $2.46(1.38-4.39)$ & & $2.48(1.39-4.42)$ & \\
\hline Twins or multiple pregnancy & & 0.006 & & 0.006 & & 0.007 \\
\hline No & Base category & & Base category & & Base category & \\
\hline Yes & $2.61(1.32-5.16)$ & & $2.64(1.32-5.25)$ & & $2.61(1.31-5.21)$ & \\
\hline
\end{tabular}

Abbreviation: OR: Odds ratio

${ }^{\text {a }}$ Model 1: Familial profiles; Model 2: Familial profiles + type of childbirth/delivery + father smoking + mother's age; Model 3: Familial profiles + type of childbirth/delivery + father smoking + mother's age (variable level = medical universities, method: random intercept).

Table 4. The Value of Population Attributable Fraction for Each Studied Variable

\begin{tabular}{|c|c|c|c|}
\hline Variable/ Familial Profiles & Prevalence in Patient Group (\%) & Odds Ratio (Model 2) & $\operatorname{PAF}(\%)^{\mathbf{a}}$ \\
\hline Congenital anomalies & 4.2 & 5.74 & 3.47 \\
\hline History of mental retardation in the family & 5.5 & 2.04 & 2.80 \\
\hline Hypothyroidism during pregnancy & 11.2 & 2.02 & 5.65 \\
\hline Intra-family marriage & 41.9 & 1.51 & 14.15 \\
\hline Gestational Diabetes & 9.7 & 1.62 & 3.71 \\
\hline Having a CH child in the family & 6.2 & 2.46 & 3.68 \\
\hline Twins or multiple pregnancy & 4.4 & 2.64 & 2.73 \\
\hline
\end{tabular}

${ }^{\text {a }}$ Population attributable fraction (PAF) calculated using the Miettinen's equation and approximated for the case-control study. 
$\mathrm{PAF}=14.9 \%$ is remarkable. In general, our findings actively addressed the role of familial factors as dominant etiologic factors in $\mathrm{CH}$; albeit, it could not entirely ignore the possible role of autoimmune and environmental factors in the development and function of the thyroid gland and $\mathrm{CH}$.

To the best of our knowledge, this is the first etiological research conducted with an incidence population-based case-control approach with the aim of identifying the most relevant familial-related risk factors for $\mathrm{CH}$ in Iran and other countries of the Middle East region. Another advantage of this study is that it assessed the hypothyroidism of mothers during pregnancy and its subsequent role in $\mathrm{CH}$. Additionally, in this research, for the first time, we calculated the PAF for seven familial-related risk factors. As a limitation for our study, we did not have the data to evaluate other important risk factors of $\mathrm{CH}$ e.g., maternal iodine status by urinary iodine measurement and iodine supplementation with iodofolic that have been evaluated in previous studies (25).

\subsection{Conclusion}

This study provides evidence regarding the role of familial-related factors in $\mathrm{CH}$. According to the obtained data, we can conclude that gestational diabetes and some familial-related factors such as congenital anomalies, parental consanguinity marriage, history of mental retardation in the family, mother's hypothyroidism during pregnancy, having a hypothyroid child in the family, twin or multiple pregnancies, play an important role in the occurrence to $\mathrm{CH}$ in Iran. Although many risk factors are hardly modifiable, the calculation of PAF for each of the risk factors in this research can help health policymakers conduct pertinent intervention programs and improve $\mathrm{CH}$ surveillance.

\section{Acknowledgments}

The authors thank all surveillance staff at medical universities who helped us in recruiting the study subjects and collecting the required data.

\section{Footnotes}

Authors' Contribution: Study concept and design: Shahin Yarahmadi, Khaled Rahmani; Analysis and interpretation of data: Khaled Rahmani, Mahmood Salesi; Manuscript drafting: Khaled Rahmani, Nasrin Aghang;
Critical revision of the manuscript: Shahin Yarahmadi, Khaled Rahmani; Study supervision: Shahin Yarahmadi.

Conflict of Interests: No potential conflict of interest was reported by the authors.

Ethical Approval: The design and protocol of conducting this study were evaluated and confirmed by the ethics committee of the Kurdistan University of Medical Sciences (ID: IR.MUK.REC.1396.153).

Funding/Support: This study was supported by the Department of Endocrinology and Metabolism, Ministry of Health, Tehran, Islamic Republic of Iran.

Informed Consent: Written informed consent was obtained from the participants prior to the initiation of the study.

\section{References}

1. Behl T, Kaur I, Kaur C, Sihag S, Medapati S. Congenital hypothyroidism: An updated review of its pathogenesis. Int J Res Pharm Sci. 2014;4(2).

2. Dias VM, Campos AP, Chagas AJ, Silva RM. Congenital hypothyroidism: etiology. J Pediatr Endocrinol Metab. 2010;23(8):815-26. doi: 10.1515/jpem.2010.131. [PubMed: 21073124].

3. Cherella CE, Wassner AJ. Congenital hypothyroidism: insights into pathogenesis and treatment. Int J Pediatr Endocrinol. 2017;2017:11. doi: 10.1186/s13633-017-0051-0. [PubMed: 29026407]. [PubMed Central: PMC5625825].

4. Wassner AJ, Brown RS. Congenital hypothyroidism: recent advances. Curr Opin Endocrinol Diabetes Obes. 2015;22(5):407-12. doi: 10.1097/MED.0000000000000181. [PubMed: 26313902].

5. Leger J, Olivieri A, Donaldson M, Torresani T, Krude H, van Vliet G, et al. European society for paediatric endocrinology consensus guidelines on screening, diagnosis, and management of congenital hypothyroidism. Horm Res Paediatr. 2014;81(2):80-103. doi: 10.1159/000358198. [PubMed: 24662106].

6. Andrade CLO, Lemos AC, Machado GC, Fernandes LDC, Silva LL, Oliveira HB, et al. Congenital hypothyroidism as a risk factor for central hearing process disorders. Rev Paul Pediatr. 2019;37(1):82-9. doi: 10.1590/1984-0462/;2019;37;1;00014. [PubMed: 30183803]. [PubMed Central: PMC6362372].

7. Potts NL, Mandleco BL. Pediatric nursing: Caring for children and their families. 3rd ed. Cengage Learning; 2012.

8. Padilla CD, Therrell BL. Jr; Working Group of the Asia Pacific Society for Human Genetics on Consolidating Newborn Screening Efforts in the Asia Pacific Region. Consolidating newborn screening efforts in the Asia Pacific region : Networking and shared education. J Community Genet. 2012;3(1):35-45. doi: 10.1007/s12687-011-0076-7. [PubMed: 22271560]. [PubMed Central: PMC3266966].

9. Rastogi MV, LaFranchi SH. Congenital hypothyroidism. Orphanet J Rare Dis. 2010;5:17. doi: 10.1186/1750-1172-5-17. [PubMed: 20537182]. [PubMed Central: PMC2903524].

10. Mehran L, Khalili D, Yarahmadi S, Amouzegar A, Mojarrad M, Ajang $\mathrm{N}$, et al. Worldwide recall rate in newborn screening programs for congenital hypothyroidism. Int J Endocrinol Metab. 2017;15(3). e55451. doi: 10.5812/ijem.55451. [PubMed: 29201074]. [PubMed Central: PMC5702453]. 
11. Yarahmadi S, Azhang N, Nikkhoo B, Rahmani K. A success story: Review of the implementation and achievements of the national newborn screening program for congenital hypothyroidism in Iran. Int J Endocrinol Metab. 2020;18(2). doi: 10.5812/ijem.99099. [PubMed: 32636885]. [PubMed Central: PMC7322671].

12. Yarahmadi S, Azhang N, Nikkhoo B, Rahmani K. Structures, processes and achievements of the national program of congenital hypothyroidism screening in the Islamic Republic of Iran. Sci J Kurdistan Univ Medical Sci. 2019;24(4):10-21. doi: 10.29252/sjku.24.4.10.

13. Rahmani K, Yarahmadi S, Etemad K, Mehrabi Y, Aghang N, Koosha $A$, et al. Intelligence quotient at the age of six years of Iranian children with congenital hypothyroidism. Indian Pediatr. 2018;55(2):121-4. [PubMed: 28952455].

14. Mehran L, Khalili D, Yarahmadi S, Delshad H, Mehrabi Y, Amouzegar A, et al. Evaluation of the congenital hypothyroidism screening programme in Iran: a 3-year retrospective cohort study. Arch Dis Child Fetal Neonatal Ed. 2019;104(2):F176-81. doi: 10.1136/archdischild-2017313720. [PubMed: 29540462].

15. Benvenga S, Ordookhani A, Pearce EN, Tonacchera M, Azizi F, Braverman LE. Detection of circulating autoantibodies against thyroid hormones in an infant with permanent congenital hypothyroidism and her twin with transient congenital hypothyroidism: possible contribution of thyroid hormone autoantibodies to neonatal and infant hypothyroidism. J Pediatr Endocrinol Metab. 2008;21(10):1011-20. doi: 10.1515/jpem.2008.21.10.1011. [PubMed: 19209623].

16. Kopp P. Perspective: genetic defects in the etiology of congenital hypothyroidism. Endocrinology. 2002;143(6):2019-24. doi: 10.1210/endo.143.6.8864. [PubMed: 12021164].

17. Hashemipour M, Hasani N, Amini M, Heidari K, Sajadi A, Dastanpour $\mathrm{M}$, et al. Thyroid function abnormalities among first-degree relatives of Iranian congenital hypothyroidism neonates. Pediatr Int. 2010;52(3):467-71. doi: 10.1111/j.1442-200X.2009.03016.x. [PubMed: 20003140].

18. Medda E, Olivieri A, Stazi MA, Grandolfo ME, Fazzini C, Baserga M, et al. Risk factors for congenital hypothyroidism: results of a population case-control study (1997-2003). Eur J Endocrinol. 2005;153(6):76573. doi: 10.1530/eje.1.02048. [PubMed:16322381].

19. Ajallouyan M, Radfar S, Nouhi S, Tavallaie SA, Amirsalari S, Yousefi J, et al. Consanguinity among parents of Iranian deaf children. Iran Red Crescent Med J. 2016;18(11). doi: 10.5812/ircmj.22038. [PubMed: 28191326]. [PubMed Central: PMC5292111].

20. Hashemipour M, Amini M, Talaie M, Kelishadi R, Hovespian S, Iranpour R, et al. Parental consanguinity among parents of neonates with congenital hypothyroidism in Isfahan. EMHJ. 2007;13(3):567-74.

21. Alimohamadi Y, Taghdir M, Sepandi M. Statistical data analysis of the risk factors of Neonatal Congenital Hypothyroidism in Khuzestan Province, Iran. Data Brief. 2018;21:2510-4. doi: 10.1016/j.dib.2018.11.113. [PubMed: 30560160]. [PubMed Central: PMC6288456].

22. Magne F, Serpa R, Van Vliet G, Samuels ME, Deladoey J. Somatic mutations are not observed by exome sequencing of lymphocyte DNA from monozygotic twins discordant for congenital hypothyroidism due to thyroid dysgenesis. Horm Res Paediatr. 2015;83(2):7985. doi: 10.1159/000365393. [PubMed: 25277881]. [PubMed Central: PMC5050031].

23. Olivieri A, Medda E, De Angelis S, Valensise H, De Felice M, Fazzini $\mathrm{C}$, et al. High risk of congenital hypothyroidism in multiple pregnancies.JClin Endocrinol Metab. 2007;92(8):3141-7. doi:10.1210/jc.20070238. [PubMed: 17488789].

24. Perry R, Heinrichs C, Bourdoux P, Khoury K, Szots F, Dussault JH et al. Discordance of monozygotic twins for thyroid dysgenesis: implications for screening and for molecular pathophysiology. $J$ Clin Endocrinol Metab. 2002;87(9):4072-7. doi: 10.1210/jc.2001-011995. [PubMed: 12213848].

25. Mehran L, Yarahmadi S, Khalili D, Nazeri P, Delshad H, Abdollahi Z, et al. The impact of iodine status on the recall rate of the screening program for congenital hypothyroidism: Findings from two national studies in Iran. Nutrients. 2017;9(11). doi: 10.3390/nu9111194. [PubMed: 29084139]. [PubMed Central: PMC5707666]. 